
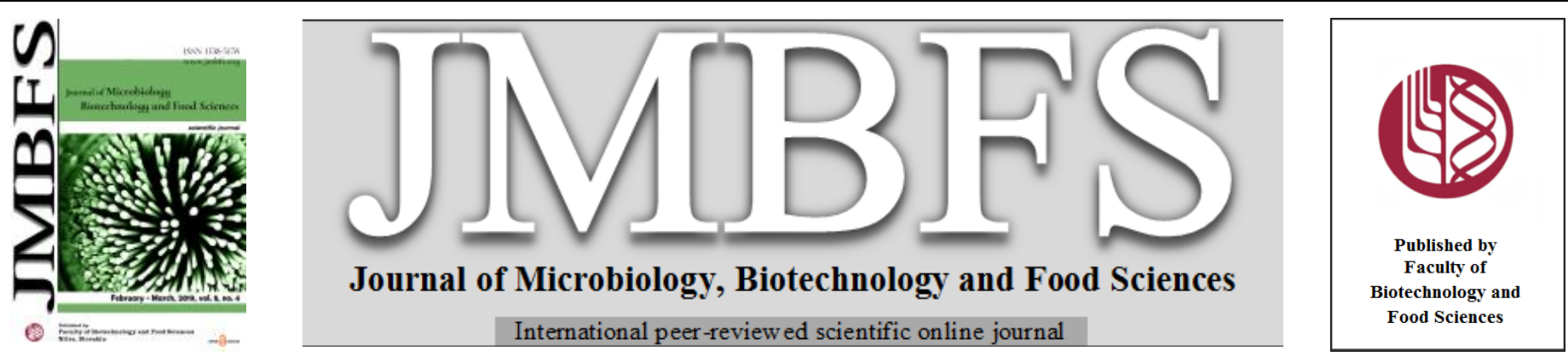

\title{
COMPARATIVE EVALUATION OF ANYPLEX II MTB/MDR/XDR AND RESAZURIN MICROTITER ASSAY FOR DETECTION OF DRUG RESISTANT MYCOBACTERIUM TUBERCULOSIS
}

\author{
Zeinab H. Helal $^{{ }^{*}}$, Nagwan, G. El Menofy ${ }^{l}$,Zeinab Abdul-Khalek Ibrahim ${ }^{2}$, Mohamed Seif El-din Ashour and Abeer, K. Abdulall $^{1}$
}

Address(es): Zeinab Helal,

${ }^{1}$ Department of Microbiology and Immunology, Faculty of Pharmacy, Al Azhar University, Cairo, Egypt.

${ }^{2}$ Department of Medical Microbiology and Immunology, Faculty of Medicine, Cairo University.

*Corresponding author: zeinabhelal@ hotmail.com

doi: 10.15414/jmbfs.2019.8.5.1150-1155

\section{ARTICLE INFO}

Received 2. 9. 2018

Revised 12. 11. 2018

Accepted 14. 12. 2018

Published 1. 4. 2019

Regular article OPEN $\partial$ ACCESS

\begin{abstract}
Drug-resistant (DR) tuberculosis (TB) is a persistent threat and presents the main challenge for TB control programs. Rapid diagnosis is essential for controlling drug-resistant cases. The aim of the study was to evaluate the performance of multiplex real-time PCR assay using Anyplex II MTB/MDR/XDR (Anyplex) kit to detect DR-TB and its concordance with Resazurin microtiter assay (REMA). The susceptibility of Mycobacterium tuberculosis, to isoniazid (INH), rifampicin (RIF), ofloxacin (OFX), and kanamycin (KAN), was evaluated by using REMA and Anyplex kit with 32 drug-resistant TB and 18 susceptible strains. Proportion method was used as gold standard. All susceptible strains were susceptible to REMA and Anyplex methods. Anyplex and REMA identified 75\% and $85 \%$ of the multidrug-resistant (MDR)-TB isolates, respectively. The sensitivity of the REMA assay as compared to PM was $96.4 \%, 90.9 \%, 85.7 \%$, and $100 \%$, respectively, for INH, RIF, OFX, and KAN, whereas the sensitivity of Anyplex was $78.5 \%, 77.2 \%$, and 85.7\% for INH, RIF, and OFX, respectively. The agreement between Anyplex and REMA was relative to INH, RIF, and OFX (kappa scores, $\mathrm{k}=0.8,0.79$ and 0.83 respectively). There was no isolate identified as KAN resistant by Anyplex. REMA, as a rapid phenotypic method, is suggested for detecting drug-resistant TB isolates that have not been detected by the Anyplex method.
\end{abstract}

Keywords: Mycobacterium tuberculosis, Anyplex II MTB/MDR/XDR, Resazurin microtiter assay

\section{INTRODUCTION}

Tuberculosis (TB) currently stands as the ninth leading cause of death from a single infectious agent worldwide. In 2016, 1.3 million deaths were attributed to this disease and 6.3 million new cases of TB were reported by WHO (World Health Organization) (WHO, 2017). In Egypt, TB is established as a significant public health problem, after Hepatitis C Virus and schistosomiasis (WHO, 2010). The main challenges that hinder the accomplishment of current $\mathrm{TB}$ control programs are multidrug-resistant tuberculosis (MDR-TB), and extensively drugresistant tuberculosis (XDR-TB). MDR-TB is defined as resistance to the two most active anti-TB drugs; rifampicin (RIF) and isoniazid (INH). XDR-TB includes resistance to the afore mentioned plus resistance to any fluoroquinoloneF (FQ) and at least one of the second line injectable drugs (amikacin, kanamycin (KAN) or capreomycin) (Gandhi et al., 2010). According to the WHO, in 2016 there were 240,000 deaths attributed to MDR and RIF-resistant TB and 490,000 new MDR-TB cases, worldwide (WHO, 2017). In Egypt, it is reported that, in 2011, about $14 \%$ of newly diagnosed patients had MDR and RIF-resistant TB subsequently, in 2016; about 20\% of previously treated patients were found with the same strains (WHO, 2017). Currently, the diagnosis of MDR-TB and XDR-TB using phenotypic drugsusceptibility testing is time-consuming. Consequently, rapid diagnostic tools are essential for controlling MDR-TB and XDR-TB cases. For reasons that it is economical, prompt, dependable and an easily performed method, Resazurin microtiter assay (REMA) has gained interest in the determination of MDR-TB. The WHO also recommends it as one of the non-commercial diagnostic sensitivity test methods (WHO, 2011).

The main cause for tuberculosis resistance is the mutation of genes encoding drug activating enzymes or drug targets (Ramasawamy and Musser, 1998). Several genes are identified to be concomitant to resistance to anti-TB drugs including rpsL and rrs for streptomycin resistance, rpoB for RIF resistance, katG, inhA, aphC, and kasA for INH resistance, pncA for pyrazinamide resistance, embB for ethambutol resistance, gyrA and gyrB to $\mathrm{FQ}$ resistance, tly A for capreomycin resistance and eis for KAN resistance. In addition, the rrs A1401G mutation is associated with cross-resistance to KAN, amikacin and capreomycin (Ando $\boldsymbol{e t}$ al., 2010; Baker et al., 2005; Bernard et al., 2015; Brossier et al., 2006; Chiu et al., 2016; Georghiou et al., 2012; Gikalo et al., 2012; Isfahan et al., 2006;
Maus et al., 2005; Suzuki et al., 1998; Takiff et al., 1994; Telenti, 1998; Zaunbrecher et al., 2009). Resistance to multiple drugs is the consequence of an accumulation of mutations (van Rie et al., 2001)

In recent years, new marketed molecular methods have been proposed for the rapid performance of drug susceptibility testing of Mycobacterium tuberculosis (M. tuberculosis), including Anyplex II MTB/MDR/XDR (Anyplex) (Causse, et al., 2015).

Anyplex is a multiplex real-time PCR that enables the detection of $M$ tuberculosis complex and resistance to RIF, INH, FQ and anti-TB injectable drugs. Anyplex is designed to recognize various mutations including; 18 mutations in rpoB, seven mutations in katG and inhA promoter, seven mutations in gyrA and three mutations in each rrs and eis promoter which causing resistance to RIF, INH, FQ, and aminoglycosides, respectively. This assay depends on two approaches, which assist specific recognition of mutations in target genes, dual-priming oligonucleotides and tagging oligonucleotide cleavage and extension (Chun, 2013; Dolinger, 2013; Lee, 2012).

The presence of rapid and accurate diagnostic susceptibility test is very critical for controlling MDR/XDR TB, particularly in developing countries where most MDR/XDR TB cases occur.

In this study, we assessed the reliability of the Anyplex II MTB/MDR /XDR kit and REMA using clinical $M$. tuberculosis strains from Egypt in detecting drugresistant $M$. tuberculosis to first and second line anti-TB drugs.

\section{MATERIALS AND METHODS}

\section{Patients and specimens}

Five hundred eighty-five sputum specimens were collected from TB patients $(\mathrm{n}=195)$ that had respiratory symptoms and radiological data suggestive of pulmonary TB during the period 2012-2014. The patients were admitted to AlAbbassia chest hospital, Cairo, Egypt. The study group consisted of 160 men and 35 women. Their ages ranged from 15 to 84 years-old. The sputum specimens were submitted to the Microbiology Laboratory, Al-Abbassia chest hospital, Cairo, Egypt, for routine culture.

From each patient, three sputum specimens were collected in the early morning on three consecutive days. Samples were decontaminated by N-Acetyl-L- 
Cysteine - $\mathrm{NaOH}$ method (Kent and Kubica, 1985) and were investigated for the presence or absence of tubercle bacilli by Ziehl-Neelsen (Z-N) staining followed by culturing onto Lowenstein-Jensen (L-J) medium. M. tuberculosis isolates were identified by the growth rate, colony morphology and biochemical tests by standard bacteriological procedures.

\section{Drug susceptibility testing}

Detection of M. tuberculosis resistance to RIF, INH, KAN, and ofloxacin (OFX) was performed by proportional method (PM) using L-J media. Susceptibility of drug-resistant TB was evaluated against RIF, INH, KAN, and OFX by REMA plate test and Anyplex II MTB/MDR /XDR kit and the results were compared to PM which is considered as the gold standard method.

The susceptible reference strain $\mathrm{H} 37 \mathrm{Rv}$ was used as a control in each diagnostic susceptibility test.

\section{Proportion method (PM):}

Indirect proportion test method was performed as previously described (Kent and Kubica, 1985)

\section{REMA plate method}

The REMA plate method was performed as described previously (Martin et al. 2012). Briefly, Two-fold serial dilution of RIF $(8 \mu \mathrm{g} / \mathrm{ml}), \mathrm{INH}(4 \mu \mathrm{g} / \mathrm{ml}), \mathrm{KAN}$ $(80 \mu \mathrm{g} / \mathrm{ml})$ and OFX $(32 \mu \mathrm{g} / \mathrm{ml})$ solutions were prepared in a 96 -well microtiter plate using Middle brook $7 \mathrm{H} 9$ supplemented broth (MB7H9) with a final volume of $100 \mu \mathrm{l}$. Growth control containing no antibiotic and sterility control without inoculum were included in each plate. A loopful of the L-J culture medium was re-suspended in a tube containing $3 \mathrm{ml} \mathrm{MB7H9} \mathrm{medium,} \mathrm{and} \mathrm{the} \mathrm{turbidity} \mathrm{was}$ adjusted to a McFarland 1.0 standard; this suspension was further diluted 1: 10 in MB7H9. Then $100 \mu \mathrm{l}$ of this suspension was inoculated in each well, and then the plate was sealed and incubated at $37^{\circ} \mathrm{C}$. After 7 days of incubation, $30 \mu \mathrm{l}$ of 0.01 $\%$ resazurin solution was added to each well, and then the plates were incubated for $24 \mathrm{~h}$ at $37^{\circ} \mathrm{C}$. The assay was done in triplicate for similar concentrations Changes in color from blue to pink indicate bacterial growth. The MIC was defined as the lowest drug concentration that prevented a full-color shift in the resazurin from blue to pink. The measure of resistance or susceptibility is defined as follows: for INH, a strain considered resistant if the $\mathrm{MIC} \geq 0.25 \mu \mathrm{g} / \mathrm{ml}$; for RIF, a strain considered resistant if the MIC $\geq 0.5 \mu \mathrm{g} / \mathrm{ml}$; for OFX a strain considered resistant if the MIC $\geq 2.0 \mu \mathrm{g} / \mathrm{ml}$ and for KAN a strain considered resistant if the MIC $\geq 2.5 \mu \mathrm{g} / \mathrm{ml}$ (Martin et al., 2012).

\section{Multiplex real-time PCR using Anyplex II MTB/MDR/XDR extraction and detection kit}

Anyplex kit (Seegene, Korea, Seoul) was used as described by manufacturer's instructions to extract DNA of decontaminated sputum specimens and DNA amplification using CFX96 ${ }^{\mathrm{TM}}$ Real-time PCR (Bio-Rad). Each sample was simultaneously tested in two separate reactions (MTB/MDR and MTB/XDR).

\section{Statistical analyses:}

Data were analyzed using IBM SPSS advanced statistics version 21 (SPSS Inc., IL, USA). Chi-square test or Fisher's exact test was used to examine the relationship between qualitative variables. All tests were two-tailed. A p-value < 0.05 was considered significant sensitivity, the kappa coefficient ranges from the $0-1$ with a value of 0 meaning no agreement and value of 1 meaning full agreement.

\section{RESULTS}

A total of 135 Mycobacterium species were isolated from 135 different patients, all of them were identified as M. tuberculosis according to colony morphology, slow growth rate, Z-N staining, niacin production and nitrate reduction tests. In relation to gender and age groups, there was not a significant difference ( $P$ value $=0.98$ ) between female and male TB positive cases and no statistically significant difference $(\mathrm{P}$ value $=0.77)$ was detected between different age groups of positive TB cases. Past TB history was documented in $29.6 \%$ (40/135) of TB positive cases. However, it was not statistically significant relationship ( $\mathrm{P}$ value $=0.35$ ) between the presence of recurrent or primary TB infection and TB history. Forty $(75.5 \%)$ of previously treated patients were TB positive cases representing $27.4 \%$ of total TB positive cases.

\section{Antimicrobial susceptibility results}

Application of the L-J PM to detect antimicrobial susceptibility showed that 103 (76.3\%) strains were susceptible to the four tested anti-TB drugs. However, the overall resistance rates to the four tested drugs were $23.7 \%$. Twenty-eight strains were resistant to INH, 22 were resistant to RIF, seven were resistant to OFX, and only two were resistant to KAN. Twenty $(62.5 \%$; 20/32) strains were resistant to INH and RIF and were defined as MDR-TB. Eighty percent $(16 / 20)$ of MDR-TB positive cases had past TB history. Table 1 shows the relationship between patient's demographic characteristics and MDR-TB positive cases. MDR-TB isolates were detected in $40 \%(16 / 40)$ of patients with a history of TB and $4.2 \%$ (4/96) of the new TB positive cases. This can be attributed to patient noncompliance with treatment, inadequate drug treatments, or poor case management. Four of the OFX resistant strains were MDR-TB, and only one of the KAN resistance strains were MDR-TB, i.e. (Pre- XDR strains). As none of the $20 \mathrm{MDR}$ strains were resistant to both OFX and KAN, we did not detect any XDR-TB strains.

Table 1 The relation between patient's demographic characteristics and MDR-TB positive cases

\begin{tabular}{llcc}
\hline Demographic characteristics & $\begin{array}{c}\text { MDR-TB } \\
\text { No. }(\%)\end{array}$ & P- value \\
\hline \multirow{2}{*}{ Gender } & Males & $17(85 \%)$ & 0.38 \\
& Females & $3(15 \%)$ & \\
\multirow{2}{*}{ Age } & $20-30$ & $3(15 \%)$ & \\
& $31-40$ & $5(25 \%)$ & $0.0012 *$ \\
TB past history & $41-50$ & $5(25 \%)$ & \\
& $\geq 51$ & $7(35 \%)$ & 0.34 \\
& New cases & $4(20 \%)$ & \\
Risk factors & Relapsed cases & $16(80 \%)$ & 0.21 \\
& Dmoking & $15(75 \%)$ & \\
& Drug addiction & $1(5 \%)$ & \\
& Diabetes & $4(20 \%)$ & \\
\hline
\end{tabular}

Legend: *- Significant, MDR- multidrug resistant

Evaluation of antimicrobial susceptibility methods for detection of drugresistant $M$. tuberculosis isolates

50 isolates (32 drug-resistant M. tuberculosis isolates and 18 susceptible ones from 50 different patients) were used to assess the antimicrobial susceptibility by REMA, which has been recommended for the determination of drug resistance and minimal inhibitory concentration (MICs) of antimicrobial agents against $M$ tuberculosis, and by multiplex real-time -PCR for detection of mutant genes responsible for drug-resistant using Anyplex ${ }^{\mathrm{TM}}$ II MTB/MDR/XDR extraction and detection kit.

\section{REMA plate method for detection of drug-resistant $M$. tuberculosis isolates}

All the previously identified drug-resistant M. tuberculosis isolates by PM and 18 susceptible isolates were examined by REMA plate method.

REMA plate method identified that $27 \mathrm{M}$. tuberculosis isolates were resistant to INH, 20 isolates were resistant to RIF, six isolates were resistant to OFX and 2 were isolates resistant to KAN. Seventeen isolates were identified as MDR-TB by REMA plate method. The REMA plate method in comparison to PM had overall sensitivity of $85 \%$ and specificity of $100 \%$. Table 2 shows that MIC identified by REMA. MIC detected by REMA among INH resistant isolates ( $\mathrm{n}=$ 27) was $>1 \mu \mathrm{g} / \mathrm{ml}$ for 19 isolates, $1 \mu \mathrm{g} / \mathrm{ml}$ for 2 isolates and $0.5 \mu \mathrm{g} / \mathrm{ml}$ for 6 isolates. Among RIF resistant isolates $(\mathrm{n}=20)$ MIC was $>2 \mu \mathrm{g} / \mathrm{ml}$ for 14 isolates, $2 \mu \mathrm{g} / \mathrm{ml}$ for 1 isolates and $1 \mu \mathrm{g} / \mathrm{ml}$ for 5 isolates. In case of OFX resistant isolates $(\mathrm{n}=6)$, MIC was $>8 \mu \mathrm{g} / \mathrm{ml}$ for 4 isolates and $8 \mu \mathrm{g} / \mathrm{ml}$ for 2 isolates, while MIC was $10 \mu \mathrm{g} / \mathrm{ml}$ for all isolates resistant to KAN isolates $(\mathrm{n}=2)$. 
PM

Resistant (n=28)

Susceptible $(\mathrm{n}=\mathbf{2 2})$

Resistant ( $\mathrm{n}=\mathbf{2 2}$ )

Susceptible $(\mathrm{n}=\mathbf{2 8})$

Resistant (n=7)

Susceptible $(n=43)$

Susceptible $(n=48)$

Legend: MIC- minimal inhibitory concentration, INH- isoniazid, RIF- rifampicin, OFX- ofloxacin, KAN- kanamycin, REMA- resazurin micro titer assay.

MIC $(\mu \mathrm{g} / \mathrm{ml})$ of INH $(\mathrm{n}=50)$

\begin{tabular}{|c|c|c|c|c|c|c|c|}
\hline$\leq \mathbf{0 . 0 3}$ & 0.06 & 0.125 & 0.25 & 0.5 & 1.0 & $>1.0$ & Total \\
\hline 0 & 0 & 0 & 0 & 6 & 2 & 19 & 27 \\
\hline 12 & 7 & 4 & 0 & 0 & 0 & 0 & 23 \\
\hline \multicolumn{8}{|c|}{ MIC $(\mu \mathrm{g} / \mathrm{ml})$ of RIF $\quad(n=50)$} \\
\hline$\leq 0.06$ & 0.125 & 0.25 & 0.5 & 1.0 & 2 & $>2$ & Total \\
\hline 0 & 0 & 0 & 0 & 5 & 1 & 14 & 20 \\
\hline 26 & 1 & 3 & 0 & 0 & 0 & 0 & 30 \\
\hline \multicolumn{8}{|c|}{ MIC $(\mu \mathrm{g} / \mathrm{ml})$ of OFX $(n=50)$} \\
\hline$\leq 0.25$ & 0.5 & 1.0 & 2 & 4 & 8 & $>8$ & Total \\
\hline 0 & 0 & 0 & 0 & 0 & 2 & 4 & 6 \\
\hline 39 & 3 & 2 & 0 & 0 & 0 & 0 & 44 \\
\hline \multicolumn{8}{|c|}{ MIC $(\mu \mathrm{g} / \mathrm{ml})$ of KAN $(\mathrm{n}=50)$} \\
\hline$\leq 0.62$ & 1.25 & 2.5 & 5 & 10 & 20 & $>20$ & Total \\
\hline 0 & 0 & 0 & 0 & 2 & 0 & 0 & 2 \\
\hline 42 & 5 & 1 & 0 & 0 & 0 & 0 & 48 \\
\hline
\end{tabular}

PM and REMA plate method regarding the detection of resistant isolates to all anti-TB drugs.

Since a PM considered as a gold standard method, we compared REMA plate
method to the PM as shown in Table 3. There was significant difference between

REMA

Table 3 Comparison of diagnostic susceptibility test results of PM and REMA

\begin{tabular}{|c|c|c|c|c|c|c|c|c|c|c|}
\hline \multirow[t]{2}{*}{ Drug } & \multirow[t]{2}{*}{ REMA } & \multicolumn{3}{|c|}{ PM } & \multirow[t]{2}{*}{$\begin{array}{c}\text { Agreement } \\
\% \\
\text { (K value) }\end{array}$} & \multirow[t]{2}{*}{ Sensitivity } & \multirow[t]{2}{*}{ Specificity } & \multirow[t]{2}{*}{ PPV } & \multirow[t]{2}{*}{ NPP } & \multirow[t]{2}{*}{ P-Value } \\
\hline & & $\mathbf{R}$ & $\mathbf{S}$ & Total & & & & & & \\
\hline \multirow{4}{*}{ INH } & $\mathbf{R}$ & 27 & 0 & 27 & $98 \%$ & \multirow{3}{*}{$96.4 \%$} & \multirow{3}{*}{$100 \%$} & \multirow{3}{*}{$100 \%$} & \multirow{3}{*}{$95.7 \%$} & \multirow{3}{*}{$<0.0001 *$} \\
\hline & $\mathbf{S}$ & 1 & 22 & 23 & $(0.96)$ & & & & & \\
\hline & Total & 28 & 22 & 50 & & & & & & \\
\hline & $\mathbf{R}$ & 20 & 0 & 20 & \multirow{3}{*}{$\begin{array}{l}96 \% \\
(0.91)\end{array}$} & \multirow{3}{*}{$90.9 \%$} & \multirow{3}{*}{$100 \%$} & \multirow{3}{*}{$100 \%$} & \multirow{3}{*}{$93.3 \%$} & \multirow{3}{*}{$<0.0001^{*}$} \\
\hline \multirow[t]{2}{*}{ RIF } & $\mathbf{S}$ & 2 & 28 & 30 & & & & & & \\
\hline & Total & 22 & 28 & 50 & & & & & & \\
\hline \multirow{3}{*}{ OFX } & $\mathbf{R}$ & 6 & 0 & 6 & \multirow{3}{*}{$\begin{array}{l}98 \% \\
(0.91)\end{array}$} & \multirow{3}{*}{$85.7 \%$} & \multirow{3}{*}{$100 \%$} & \multirow{3}{*}{$100 \%$} & \multirow{3}{*}{$97.7 \%$} & \multirow{3}{*}{$<0.0001^{*}$} \\
\hline & $\mathbf{S}$ & 1 & 43 & 44 & & & & & & \\
\hline & Total & 7 & 43 & 50 & & & & & & \\
\hline \multirow[b]{2}{*}{ KAN } & $\mathbf{R}$ & 2 & 0 & 2 & \multirow{2}{*}{$\begin{array}{c}100 \% \\
\text { (1) }\end{array}$} & \multirow[b]{2}{*}{$100 \%$} & \multirow[b]{2}{*}{$100 \%$} & \multirow[b]{2}{*}{$100 \%$} & \multirow[b]{2}{*}{$100 \%$} & \multirow[b]{2}{*}{$0.0008^{*}$} \\
\hline & $\mathbf{S}$ & 0 & 48 & 48 & & & & & & \\
\hline
\end{tabular}

Legend: *-Significant, PM- proportion method, REMA- resazurin microtiter assay, K- The kappa value, R- resistant, S- sensitive, INH - isoniazid, RIFrifampicin, OFX- ofloxacin, KAN- kanamycin, PPV- positive predictive values NPP- negative predictive values.

\section{Real-time PCR results using Anyplex II MTB/MDR/XDR}

The Anyplex Kit is designed to identify the MTC and resistance to INH, RIF, FQ, and anti-TB injectable drugs by melting curve analysis (Fig. 1).

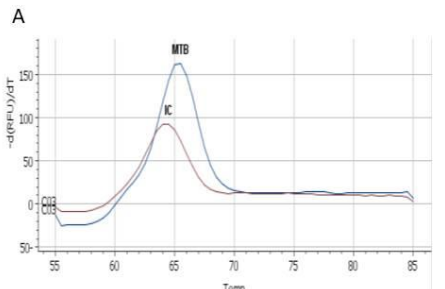

B

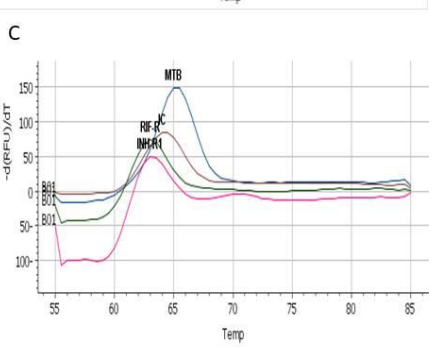

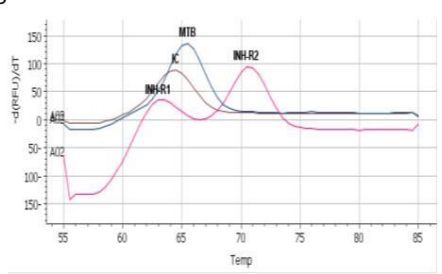

D

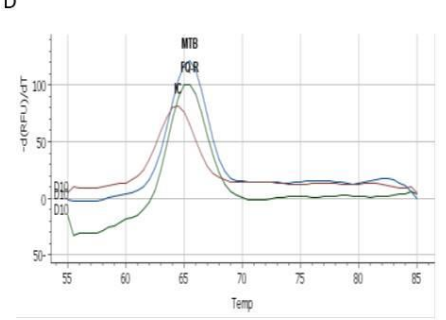

Figure 1 Melting curves obtained using Anyplex ${ }^{\mathrm{TM}}$ II MTB/MDR/XDR kit. Each curve is labeled to reflect the sample examined which were as follows: IC, internal control; MTB, mpt64 (wild-type); RIF-R, rpoB mutation; INH-R1, katG mutation; INH-R2, inhA promoter mutation; FQ-R, gyrA mutation; (A) Melting Curve of MTB/XDR reactions shows sensitive isolate; (B) Melting Curve of MTB/MDR reactions shows INH-mono-resistant isolate; (C) Melting Curve of MTB/MDR reactions shows MDR-TB isolate; (D) Melting Curve of MTB/XDR reactions shows FQ-mono-resistant isolate.

All the tested M.tuberculosis isolates, by Anyplex Kit, were correctly identified as MTC isolates. Twenty-two isolates were resistant to INH by Anyplex. Thirteen isolates had mutations in katG gene, seven isolates had mutations in inhA promoter and two isolates had concomitant mutations in katG gene and inhA promoter. Moreover; 17 isolates were resistant to RIF, and six isolates were resistant to OFX by Anyplex. Unexpectedly, there was no Kanamycin resistance detected by Anyplex. Table 4 shows a comparison between the results of diagnostic sensitivity test by PM and Anyplex. The overall sensitivity and specificity of Anyplex methods were $75 \%$ and $100 \%$, respectively. Fifteen isolates were identified as MDR-TB by Anyplex.

Table 4 Comparison of diagnostic susceptibility test results of PM and Anyplex 


\begin{tabular}{|c|c|c|c|c|c|c|c|c|c|c|}
\hline \multirow{2}{*}{ Drug } & \multirow{2}{*}{ 光 } & \multicolumn{3}{|l|}{ PM } & \multirow[t]{2}{*}{$\begin{array}{l}\text { Agreement \% } \\
\text { K value }\end{array}$} & \multirow[t]{2}{*}{ Sensitivity } & \multirow[t]{2}{*}{ Specificity } & \multirow[t]{2}{*}{ PPV } & \multirow[t]{2}{*}{ NPP } & \multirow[t]{2}{*}{ P-Value } \\
\hline & & $\mathbf{R}$ & $\mathbf{S}$ & Total & & & & & & \\
\hline \multirow[t]{3}{*}{ INH } & $\mathrm{R}$ & 22 & 0 & 22 & $88 \%$ & \multirow{3}{*}{$78.5 \%$} & \multirow{3}{*}{$100 \%$} & \multirow{3}{*}{$100 \%$} & \multirow{3}{*}{$78.5 \%$} & \\
\hline & $\mathrm{S}$ & 6 & 22 & 28 & $(0.76)$ & & & & & $<0.0001^{*}$ \\
\hline & Total & 28 & 22 & 50 & & & & & & \\
\hline \multirow[t]{3}{*}{ RIF } & $\mathrm{R}$ & 17 & 0 & 17 & \multirow{3}{*}{$\begin{array}{l}90 \% \\
(0.79)\end{array}$} & \multirow{3}{*}{$77.2 \%$} & \multirow{3}{*}{$100 \%$} & \multirow{3}{*}{$100 \%$} & \multirow{3}{*}{$86.8 \%$} & \multirow{3}{*}{$<0.0001 *$} \\
\hline & $\mathrm{S}$ & 5 & 28 & 33 & & & & & & \\
\hline & Total & 22 & 28 & 50 & & & & & & \\
\hline \multirow[t]{3}{*}{ OFX } & $\mathrm{R}$ & 6 & 0 & 6 & \multirow{3}{*}{$\begin{array}{l}98 \% \\
(0.91)\end{array}$} & \multirow{3}{*}{$85.7 \%$} & \multirow{3}{*}{$100 \%$} & \multirow{3}{*}{$100 \%$} & \multirow{3}{*}{$97.7 \%$} & \multirow{3}{*}{$<0.0001 *$} \\
\hline & $\mathrm{S}$ & 1 & 43 & 44 & & & & & & \\
\hline & Total & 7 & 43 & 50 & & & & & & \\
\hline \multirow[t]{3}{*}{ KAN } & $\mathrm{R}$ & 0 & 48 & 2 & \multirow{3}{*}{ NA } & & & & & \\
\hline & $\mathrm{S}$ & 2 & 0 & 48 & & & & & & \\
\hline & Total & 2 & 50 & 50 & & & & & & \\
\hline
\end{tabular}

Legend: *-Significant; PM- proportion method, MRT-PCR- multiplex real time PCR using Anyplex ${ }^{\mathrm{TM}}$ II MTB/MDR/XDR kit, K- The kappa value, R- resistant, S- sensitive, INH- isoniazid, RIF- rifampicin, OFX- ofloxacin, KAN- kanamycin, PPV- positive predictive values, NPPnegative predictive values, NA- not available (can't be computed)

The detection rate of resistant to anti-TB studied by REMA was higher than

for detection of resistance, compared to REMA method were $81.4 \%$ and $100 \%$ for INH, $80.9 \%$ and $100 \%$ for RIF and $85.7 \%$ and $100 \%$ for OFX.

Anyplex method as shows in table 5. The sensitivity and specificity of Anyplex

$\underline{\text { Table } 5 \text { Comparison of diagnostic susceptibility test results of REMA and Anyplex }}$

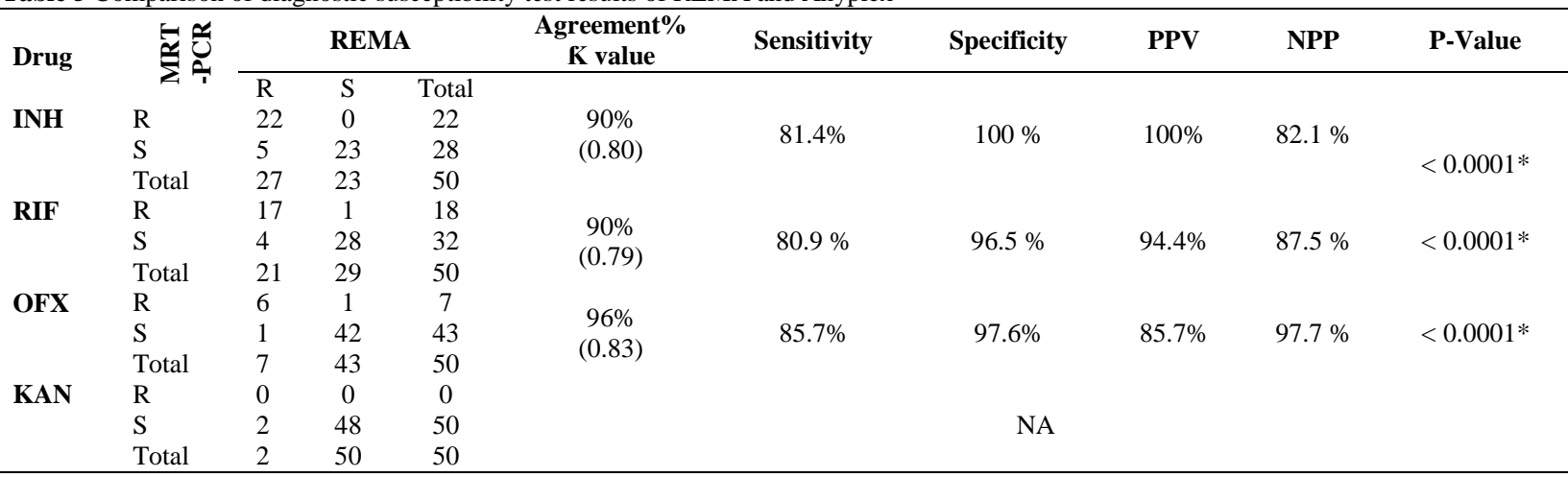

Legend: *-Significant, REMA: resazurin microtiter assay, MRT-PCR- multiplex real time PCR using Anyplex TM II MTB/MDR/XDR kit, K- The kappa value, R- resistant, S- sensitive, INH- isoniazid, RIF- rifampicin, OFX- ofloxacin, KAN- kanamycin, PPV-positive predictive values NPPnegative predictive values, NA- not available (can't be computed)

\section{Cost evaluation}

The cost/case by PM, REMA plate method, and Anyplex were $\$ 4.38, \$ 2.265$, and $\$ 23.25$ (USD based year 2014), respectively. The cost of appliances required for storage and testing of samples and kits, and the staff required in the current study was not contained within the cost computation for each isolate. Cost/isolate with REMA assay was found to be nearly two times lower than that of PM. Although the cost of the Anyplex method was higher, the time of detection was very low in comparison to REMA method as shown in table 6.

Table 6 Cost / time comparison of the diagnostic susceptibility methods used in this study

\begin{tabular}{|c|c|c|c|}
\hline Method & PM (using L-J) & REMA plate & MRT-PCR \\
\hline Kits and disposable tools cost & $\$ 4.38$ & $\$ 2.65$ & $\$ 23.25$ \\
\hline Equipment & Regular incubator & Regular incubator & Thermal cycler \\
\hline Technician qualification & $\begin{array}{c}\text { Regular microbiological } \\
\text { training }\end{array}$ & Special microbiological training & $\begin{array}{c}\text { Special microbiological training } \\
\text { and higher salary }\end{array}$ \\
\hline Duration till diagnosis & $\begin{array}{c}\text { 28-50 days } \\
\text { (starting from colony) }\end{array}$ & $\begin{array}{c}8 \text { days } \\
\text { (starting from colony) }\end{array}$ & $\begin{array}{c}\text { Instantly } \\
\text { (starting from specimen) }\end{array}$ \\
\hline
\end{tabular}
using Anyplex ${ }^{\mathrm{TM}}$ II MTB/MDR/XDR kit

\section{DISCUSSION}

The emergence of MDR/XDR-TB is a global public health concern. Thus accurate and rapid diagnostic susceptibility testing of anti-TB drugs is critical. Although the conventional anti-TB susceptibility test takes several weeks to yield results, it continues to be the gold standard for assessing resistance to anti-TB drugs. In the present study, we evaluated REMA and Anyplex assays for detection of $M$. tuberculosis resistant isolates in Egypt. REMA results were obtained in a short period and with great sensitivity and specificity, compared with the PM. The REMA plate method has exhibited a high degree of agreement with the conventional PM in the detection of drug resistance to the first line (INH $\&$ RIF) and the second line (OFX \& KAN) anti-TB drugs. The agreement between the two tests for INH, RIF, OFX and KAN resistant was 98\%, 96\%, 98 $\%$, and $100 \%$ respectively. These results were quite consistent with the other two studies by Coban et al., (2012) and Khalifa et al., (2013), who reported excellent agreement between the PM and REMA methods. The sensitivity of the REMA assay in compare to PM was $96.4 \%, 90.9 \%, 85.7 \%$ and $100 \%$ for INH, RIF, $\mathrm{OFX}$, and KAN, respectively, whereas the specificity was $100 \%$ for all tested drugs. Other studies have assessed the diagnostic performance of the REMA plate method and compared the results to conventional PM (Martin et al., 2003; Montoro et al,. 2005; Nateche et al., 2006). Their results were very similar to the current results in relations of specificity and sensitivity for first and second line anti-TB drugs. Also, REMA has the benefit of simply determining the MIC; MIC results in this study were in accordance with Nateche et al. (Nateche $\boldsymbol{e t}$ al., 2006) who reported that the MIC by REMA among INH resistant isolates $(n=17)$ was $>1 \mu \mathrm{g} / \mathrm{ml}$, while among RIF resistant isolates $(\mathrm{n}=12)$ MIC was $>2 \mu \mathrm{g} / \mathrm{m}$ $(10 / 17), 1 \mu \mathrm{g} / \mathrm{ml}(1 / 17)$ and $0.5 \mu \mathrm{g} / \mathrm{ml}(1 / 17)$. Similarly, Affolabi et al. (2008) reported that $82.6 \%(19 / 23)$ of the isolates resistant to INH had MIC $\geq 1 \mu \mathrm{g} / \mathrm{ml}$ and $93.9 \%(14 / 15)$ of the isolates resistant to RIF had MIC $\geq$ two $\mu \mathrm{g} / \mathrm{ml}$. In Egypt, the MICs of OFX and KAN reported by Khalifa et al. (2013) were quite different than that in our study. They found that the MIC among OFX resistant isolates $(\mathrm{n}=5)$ was $4 \mu \mathrm{g} / \mathrm{ml}(\mathrm{n}=3)$ and $8 \mu \mathrm{g} / \mathrm{ml}(\mathrm{n}=2)$. For KAN, MIC of resistant isolates $(\mathrm{n}=5)$ was $5 \mu \mathrm{g} / \mathrm{ml}(\mathrm{n}=4)$ and $10 \mu \mathrm{g} / \mathrm{ml}(\mathrm{n}=1)$. In this study, the identified cut-off values for INH, RIF, OFX, and KAN were $0.25,0.5,2$ and $2.5 \mu \mathrm{g} / \mathrm{ml}$, respectively. This was in agreement with the MIC specified by other studies (Affolabi et al., 2008; Martin et al., 2003; Montoro et al., 2005; Nateche et al., 
2006; Palomino et al., 2002). The cutoff value is built on the greatest fitting of the colorimetric results with the conventional method to characterize the resistant and susceptible isolates.

The Anyplex II MTB/MDR/XDR assay is a real-time multiplex PCR has numbers of probes which are used to detect resistant to first and second-line antiTB drugs. We compared the performance of Anyplex assay as a diagnostic susceptibility test with the conventional PM. Anyplex identified $75 \%$ of the MDR-TB isolates. The sensitivity of the Anyplex method compared to that of PM was observed to be $78.5 \%, 77.2 \%$ and $85.7 \%$ for INH, RIF, and OFX respectively. The specificity was $100 \%$ for INH, RIF, and OFX. Anyplex sensitivity determined in this study among INH resistant isolates $(78.5 \%)$ was higher than the sensitivity from previous reports examining clinical isolates from Spain and Lithuania (60.6\%) and Japan (68.8\%) (Causse $\boldsymbol{e t}$ al., 2015; Igarashi $\boldsymbol{e}$ al., 2017). On the other hand, this was relatively low sensitivity for INH than the sensitivity (91.4\%) reported by Pérez-García et al., (2017), while it was quite similar to the sensitivity (76.5\%) reported by Molina-Moya et al.(2015), both studies were studying clinical isolates from Spain. In this study, the INH resistant, detected by Anyplex assay, was due to mutations occurs in katG and the inhA promoter region. The variation in sensitivity between PM and Anyplex may be attributed to additional mutations in oxyR', furA, kasA, srmR, Ndh, Rv0340/1592c /1772, nat, fadE24, efpA, fabD, aacD6, fbpC, f abG1 and iniA/B/C, which have also been implicated in INH resistance $M$. tuberculosis (Seifert et al., 2015; Vilchèze and Jacobs, 2014).

The sensitivity of the Anyplex test to RIF was 77.2\%. This was lower than the data from previous studies which reported Anyplex sensitivity to RIF by more than 90\% (Causse et al., 2015; Igarashi et al., 2017; Molina-Moya et al., 2015; Pérez-García et al ., 2017). This comparatively low sensitivity to RIF may be attributed to under-coverage of the related mutations, e.g., other regions of rpoB such as V146F (Ahmad and Mokaddas, 2005). Igarashi et al., (2017) proposed the reason of the misidentified RIF resistant isolates (even with a nine-base deletion from 1516 to 1524 ) due to the presence deletions outside the target region of the Anyplex test.

Regarding second-line anti-TB drugs, Chen et al. (2011) designed a highresolution melting analysis test to identify OFX resistance in $M$. tuberculosis by targeting resistance concomitant with the mutations in gyrA gene. They detected gyrA mutations in all of $41(100 \%)$ OFX resistant isolates. The gyrA mutations considered as the most common mechanism of resistant of FQ among $M$ tuberculosis isolates (Bernard et al., 2015; Chiu et al., 2016; Telenti, 1998). In this study, the sensitivity of Anyplex for OFX was $85.7 \%$. This was higher than the sensitivity (67.7\%) reported by Causse et al. (2015).

In this study, no isolate was identified as KAN resistant by Anyplex. This may be related to alternative KAN resistance mechanisms, such as a different mutation in rrs or increased expression of the gene encoding the aminoglycoside acetyltransferase; eis (Evans and Sega, 2010).

We compared the performance of Anyplex assays with the REMA assay. Anyplex recognized $88.2 \%$ of the MDR-TB isolates identified by REMA. The sensitivity of the Anyplex method compared to that of REMA was observed to be $80.4 \%, 81.9 \%$ and $85.7 \%$ for INH, RIF, and OFX respectively. The specificity was $100 \%$ for INH, RIF, and OFX. To the best of our knowledge, this is the firs study that compare between REMA and Anyplex assays.

As mentioned previously, the variation between REMA assay as a phenotypic method and Anyplex as a molecular method may be related to other resistance mechanisms or presence of mutations in other genes. Although real-time PCR test is a rapid diagnostic technique, it was not until now, an absolute and acceptable standard for detection of mutations controlling drug resistance in $M$. tuberculosis. This method detects only known mutations, and not all mutations confer resistance to anti-TB drugs are known. Moreover, the pattern of mutations may vary from geographic region to another.

Comparison of the cost of the laboratory diagnostic susceptibility test revealed that the Anyplex assay had the highest financial cost. However, time elapsed to get the result was considerably the lowest. Regarding the cost of infection spread as the result of a delay in MDR/XDR TB diagnosis, Anyplex is considered the most cost-effective method.

\section{CONCLUSION}

In this study, REMA method was found to be nearly in complete agreement with those obtained by the PM.

There are some characteristics of the REMA assay which make it preferable to the PM. The REMA assay is rapid, low in cost, with easy-to-read results which are easily specified by a color change visible to the naked eye.

The multiplex real-time PCR kits (Anyplex II MTB/MDR/XDR) enabled automated rapid detection of MDR/ XDR -TB. The turn-around time was approximately five hours, including the DNA-extraction. Although Anyplex assay reduces the time for diagnosis of drug-resistant tuberculosis, it has varying sensitivity for detecting anti-TB drugs resistance. Anyplex II MTB/MDR /XDR couldn't identify KAN resistant isolate. Accordingly, another method of phenotypic susceptibility test is required with Anyplex negative or drugsusceptible results.
For that reason, REMA will be the most suitable method in this situation, due to its rapid results and economic advantage in cost over the PM.

Acknowledgement: The authors acknowledge Dr. Faten Shoukry: Head of Microbiology Department, Al- Abbassia Chest Hospital for facilitating the clinical specimens' collection. The authors also thank Dr. Manar M. Moneer: Cancer Epidemiology and Biostatistics Department, National Cancer Institute, Cairo University, Cairo, Egypt, for her help in the statistical analysis of the study.

\section{REFERENCES}

AFFOLABI, D., SANOUSSI, N., ODOUN, M., MARTIN, A., KOUKPEMEDJI, L., PALOMINO, J.C., ANAGONOU, S., PORTAELS, F.,2008. Rapid detection of multidrug-resistant Mycobacterium tuberculosis in Cotonou (Benin) using two low-cost colorimetric methods: resazurin and nitrate reductase assays. J. Med Microb, 57, 1024-1027.

AHMAD, S., MOKADDAS, E. 2005. The occurrence of rare rpoB mutations in rifampicin-resistant clinical Mycobacterium tuberculosis isolates from Kuwait. Int. J. Antimicrob. Agent, 26, 205-212 https://doi.org/10.1016/i.ijantimicag.2005.06.009

ANDO, H., KONDO, Y., SUETAKE, T., TOYOTA, E., KATO, S., MORI, T., KIRIKAE, T. 2010. Identification of katG mutations associated with high-level isoniazid resistance in Mycobacterium tuberculosis. Antimicrob. Agents. Chemother. 54, 1793-9.

BAKER, L.V., BROWN, T.J., MAXWELL, O., GIBSON, A.L., FANG, Z., YATES, M.D., DROBNIEWSKI, A. 2005. Molecular analysis of isoniazidresistant Mycobacterium tuberculosis isolates from England and Wales reveals the phylogenetic significance of the ahpC-46A polymorphism. Antimicrob. Agents Chemother, 49, 1455-1464

BERNARD, C., VEZIRIS, N., BROSSIER, F., SOUGAKOFF, W., JARLIER, V., ROBERT, J., AUBRYA, A. 2015. Molecular diagnosis of fluoroquinolone resistance in Mycobacterium tuberculosis. Antimicrob. Agents. Chemother, 59, 1519-24.

BROSSIER, F., VEZIRIS, N., TRUFFOT-PERNOT, C., JARLIER, V., SOUGAKOFF, W. 2006. Performance of the genotype MTBDR line probe assay for detection of resistance to rifampin and isoniazid in strains of Mycobacterium tuberculosis with low- and high-level resistance. J. Clin. Microbiol, 44, 3659-64. CAUSSE, M., RUIZ, P., GUTIERREZ, J.B., VAQUERO, M., CASAL, M. 2015. New Anyplex II MTB/MDR/XDR kit for detection of resistancenmutations in M. tuberculosis cultures. Int. J. Tuberc. Lung Dis, 19 (12), 1542-1546. https://doi.org/10.5588/ijtld.15.0235

CHEN, X., KONG, F., WANG, Q., LI, C., ZHANG, J., GILBERT, G. 2011 Rapid Detection of Isoniazid, Rifampin, and Ofloxacin Resistance in Mycobacterium tuberculosis Clinical Isolates Using High-Resolution Melting Analysis. J. Clin. Microbiol, 49, 3450-3457.

CHIU, W.Y., CHIEN, S.T., CHIANG, C.J., YU, C.J., HSUEH, P.R. 2016 Mutations in gyrA and gyrB among fluoroquinolone- and multidrug-resistant Mycobacterium tuberculosis isolates. Antimicrob. Agents. Chemother, 60, 2090 6

CHUN, J.Y. 2013. Multiplex molecular diagnostics: shifting the paradigm. MLOMed. Lab. Obs, 45(30), 32

COBAN, A.Y., UZUN, M., AKGUNES, A., DURUPINAR, B. 2012. Comparative evaluation of the microplate nitrate reductase assay and the rezasurin microtitre assay for the rapid detection of multidrug resistan Mycobacterium tuberculosis clinical isolates. Mem. Inst. Oswaldo. Cruz, 107(5), 578-581. http://dx.doi.org/10.1590/S0074-02762012000500002

DOLINGER, D.L. 2013. TOCETM - chemistry for a new generation of molecular diagnostics. Transl. Med, 3, 112 .

Evans, J., Segal, H. 2010. Novel multiplex allele-specific PCR assays for the detection of resistance to second-line drugs in Mycobacterium tuberculosis. Antimicrob. Chemother, 65(5), 897-900. https://doi.org/10.1093/jac/dkq047 GANDHI, N.R., NUNN, P., DHEDA, K., SCHAAF, H.S., ZIGNOL, M., VAN SOOLINGEN, D., JENSEN, P., BAYONA, J. 2010. Multidrug-resistant and extensively drug-resistant tuberculosis: a threat to global control of tuberculosis Lancet, 375(9728), 1830-1843. https://doi.org/10.1016/S0140-6736(10)60410-2 GEORGHIOU, S.B., MAGANA, M., GARFEIN, R.S., CATANZARO, D.G., CATANZARO, A., RODWELL, T.C. 2012. Evaluation of genetic mutations associated with Mycobacterium tuberculosis resistance to amikacin, kanamycin and capreomycin: a systematic review. PLoS One, 7, e33275. https://doi.org/10.1371/journal.pone.0033275

GIKALO, M.B., NOSOVA, E.Y., KRYLOVA, L.Y., MOROZ, A.M. 2012. The role of eis mutations in the development of kanamycin resistance in Mycobacterium tuberculosis isolates from the Moscow region. J. Antimicrob. Chemother, 67, 2107-9.

IGARASHI. Y. K., CHIKAMATSU, K., AONO, A., YI, L., YAMADA, H., TAKAKI, A., MITARAI, S. 2017. Laboratory evaluation of the Anyplex ${ }^{\mathrm{TM}}$ II MTB/MDR and MTB/XDR tests based on multiplex real-time PCR and meltingtemperature analysis to identify Mycobacterium tuberculosis and drug resistance. $\begin{array}{llll}\text { Diag. } & \text { Microbiol. } & \text { Infect. Dis, } & 89(4),\end{array}$ https://doi.org/10.1016/j.diagmicrobio.2017.08.016 
ISFAHAN, B.N., TAVAKOLI, A., SALEHI, M., TAZHIBI, M., 2006. Detection of rifampin resistance patterns in Mycobacterium tuberculosis strains isolated in Iran by polymerase chain reaction-single-strand conformation polymorphism and direct sequencing methods. Mem. Inst. Oswaldo. Cruz, 101(6), 597-602. http://dx.doi.org/10.1590/S0074-02762006000600004

KENT, B.S., KUBICA, G.P. 1985. Public health mycobacteriology: a guide for the level III laboratory. U.S. Department of health and humans services publication no. 86-8230, Wshington, D.C. 1985.

KHALIFA, R.A., NASSER, M.S., GOMAA, A.A., OSMAN, N.M., SALEM, H.M. 2013. Resazurin microtiter assay plate method for detection of susceptibility of multidrug resistant Mycobacterium tuberculosis to second-line anti-tuberculous drugs. Egy. J. Ches. Dis. and Tuberculo, 62, 241-247. https://doi.org/10.1016/j.ejcdt.2013.05.008

LEE, D.H. 2012. TOCE: Innovative Technology for High Multiplex Real-time PCR. Seegene Bulletin, 1, 1-10.

Martin, A., Camacho, M., Portaels, F., Palomino, J. 2003. Resazurin microtiter assay plate testing of Mycobacterium tuberculosis susceptibilities to second-line drugs: rapid, simple, and inexpensive method, Antimicrob. Agents Chemother, 47(11), 3616-3619.

MARTIN, A., PALOMINO, J.C., LEMUS, D., MONTORO, E. 2012. Procedure Manual, colorimetric redox indicator (CRI) Drug susceptibility testing for Mycobacterium tuberculosis. $\quad$ Version 2012 http://tbevidence.org/documents/rescentre/sop/Procedure\%20manual\%20CRI\%2 006-2012.pdf

MAUS, C.E., PLIKAYTIS, B.B., SHINNICK, T.M. 2005. Molecular analysis of cross-resistance to capreomycin, kanamycin, amikacin, and viomycin in Mycobacterium tuberculosis. Antimicrob. Agents Chemother, 49, 3192-7.

MOLINA-MOYA, B., LACOMA, A., PRAT, C., PIMKINA, E., DIAZ, J. GARCÍA-SIERRA, N., HABA, L., MALDONADO, J., SAMPER, S., RUIZ MANZANO, J., AUSINA, V., DOMINGUEZ, J. 2015. Diagnostic accuracy study of multiplex PCR for detecting tuberculosis drug resistance. J. Infect, 71(2), 220-30. https://doi.org/10.1016/j.jinf.2015.03.011

MONTORO, E., LEMUS, D., ECHEMENDIA, M., MARTIN, A., PORTAELS, F., PALOMINO, J.C. 2005. Comparative evaluation of the nitrate reduction assay, the MTT test, and the resazurin microtitre assay for drug susceptibility testing of clinical isolates of Mycobacterium tuberculosis .J. Antimicr. Chemo, 55, 500-505. https://doi.org/10.1093/jac/dki023

NATECHE, F., MARTIN, A., BARAKA, S., PALOMINO, J., KHALED, S. PORTAELS, F. 2006. Application of the resazurin microtitre assay for detection of multidrug resistance in Mycobacterium tuberculosis in Algiers. J. Med. Microb, 55, 857-860.

Palomino, J.C., Martin, A., Camacho, M., Guerra, H., Swings, J., Portaels, F 2002. Resazurin Microtiter Assay Plate: Simple and Inexpensive Method for Detection of Drug Resistance in Mycobacterium tuberculosis. Antimicrob. Agents. Chemother, 46, 2720-2722.

PÉREZ-GARCÍA, F., RUIZ-SERRANO, M,J., LÓPEZ ROA, P., ACOSTA, F., PÉREZ-LAGO, L., GARCÍA-DE-VIEDMA, D., BOUZA, E. 2017. Diagnostic performance of Anyplex II MTB/MDR/XDR for detection of resistance to first and second line drugs in Mycobacterium tuberculosis. J. Microbiol. Methods, 139, 74-78. https://doi.org/10.1016/j.mimet.2017.05.006

RAMASWAMY, S., MUSSER, J. M., 1998. Molecular genetic basis of antimicrobial agent resistance in Mycobacterium tuberculosis: update. Tuber. Lung. Dis, 79, 3-29. https://doi.org/10.1054/tuld.1998.0002

SEIFERT. M., CATANZARO, D., CATANZARO, A., RODWELL, T.C. 2015 Genetic mutations associated with isoniazid resistance in Mycobacterium tuberculosis: a systematic review. PLoS One, 10:1-13. https://doi.org/10.1371/journal.pone.0119628

SUZUKI, Y., KATSUKAWA, C., TAMARU, A. 1998. Detection of kanamycinresistant Mycobacterium tuberculosis by identifying mutations in the 16S rRNA gene. J. Clin. Microbiol, 36, 1220-5.

TAKIFF, H.E., SALAZAR, L., GUERRERO, C., PHILIPP, W., HUANG, W. M., KREISWIRTH, B., COLE, S.T., JACOBS, JR W.R., TELENTI, A. 1994 Cloning and nucleotide sequence of Mycobacterium tuberculosis gyrA and gyrB genes and detection of quinolone resistance mutations. Antimicrob. Agents Chemother, 38, 773-80.

TELENTI, A., 1998. Genetics and pulmonary medicine. 5. Genetics of drug resistant tuberculosis. Thorax, 53, 793-7.

VAN RIE, A., WARREN, R., MSHANGA, I., JORDAAN, A.M., SPUY, G.D., RICHARDSON, M. SIMPSON, J., GIE, R.P., ENARSON, D.A., BEYERS, N., VAN HELDEN, P.D., VICTOR, T.C. 2001. Analysis for a limited number of gene codons can predict drug resistance of Mycobacterium tuberculosis in a highincidence community. J. Clin. Microbiol, 39(2), 636-641.

VILCHËZE, C., JACOBS, JR. W.R. 2014. Resistance to isoniazid and Ethionamide in Mycobacterium tuberculosis: genes, mutations, and causalities. Microbiol. Spectr, 2, 1-21.

WORLD HEALTH ORGANIZATION (WHO),, 2010. Country Cooperation Strategy for WHO and Egypt 2010-2014. WHO, 2010 http://applications.emro.who.int/docs/CCS Egypt 2010 EN 14481.pdf
WORLD HEALTH ORGANIZATION (WHO). 2011 Noncommercial culture and drug-susceptibility testing methods for screening patients at risk for multidrugresistant tuberculosis. WHO, 2011

http://apps.who.int/iris/bitstream/10665/44601/1/9789241501620_eng.pdf?ua=1 \&ua=1.

WORLD HEALTH ORGANIZATION (WHO)., 2017. Global tuberculosis report 2017. Geneva: World Health Organization. Licence: CC BY-NCSA-3.0 IGO WHO, 2017. http://apps.who.int/iris/bitstream/10665/259366/1/9789241565516eng.pdf

ZAUNBRECHER, M.A., SIKES, R.D., METCHOCK, B., SHINNICK, T.M., POSEY, J.E. 2009. Overexpression of the chromosomally encoded aminoglycoside acetyltransferase eis confers kanamycin resistance in Mycobacterium tuberculosis. Proc. Natl. Acad. Sci. USA 106, 20004-9. https://doi.org/10.1073/pnas.0907925106 